\title{
IMAGINAÇÃO HISTÓRICA E SALA DE AULA: UM ESTUDO DE CASO E UMA POSSIBILIDADE TEÓRICA
}

\section{HISTORICAL IMAGINATION AND CLASSROOM: A STUDY OF CASE AND A THEORETICAL POSSIBILITY}

\author{
Rafael Aparecido Monpean ${ }^{1}$ \\ Yasmin Carli Albino ${ }^{2}$
}

\begin{abstract}
RESUMO: Abordamos neste artigo aspectos sobre a imaginação histórica dos estudantes do ensino médio do Colégio de Aplicação da UEL. Através do uso de um questionário de conhecimentos prévios, aplicado aos alunos e alunas que lecionaríamos em nossa prática de estágio, intentamos realizar uma análise das concepções acerca da história que expressavam em suas respostas. Partimos, nesse sentido, de alguns pressupostos teóricos de autores que consideram o aspecto essencial da linguagem para e na construção da imaginação histórica.
\end{abstract}

Palavras-chave: Imaginação histórica. Ensino de história. Virada linguística.

\begin{abstract}
We approach in this paper some aspects about the historical imagination of high school students of the Colégio de Aplicação da UEL. Through the use of a prior knowledge questionnaire, applied to the students that we would teach in our internship, we intend an analysis of the conception expressed in their answers. Accordingly, we started from some theoretical assumptions of authors that consider the essential aspect of the language for and in the construction of the historical imagination.
\end{abstract}

Keywords: Historical imagination. History teaching. Linguistic turn.

\footnotetext{
${ }^{1}$ Mestrando em História Cultural na Universidade Estadual de Campinas.

${ }^{2}$ Graduada em História na Universidade Estadual de Londrina.
} 


\section{Introdução}

A partir das disciplinas voltadas para a metodologia e orientação de estágio obrigatório do curso de licenciatura em História da UEL, foi-nos sugerido a aplicação de questionários aos alunos que lecionaríamos em nossa prática de estágio. Tais questionários tinham o intuito de demonstrar os saberes prévios que esses alunos possuíam sobre os temas que abordaríamos nas aulas (quer de forma específica, quais os significados que atribuíam aquilo que veríamos, ou ampla, quais os sentidos que davam à história), assim como de suas relações socioculturais. Em outras palavras, eles nos mostrariam, dentro de suas limitações, os universos conceituais nos quais adentraríamos no semestre seguinte durante a "experiência" da prática docente. As indagações que aqui colocaremos partem justamente do que encontramos (ou do que pretendíamos encontrar ao aplicar) nesses "questionários de conhecimentos prévios", do mesmo modo que, de forma direta, experienciamos ao longo do estágio.

Nosso problema principal, dentro da elaboração do questionário e para formulação deste texto, foi construir indagações que tentassem entender quais as concepções que os alunos do primeiro ano " $E$ " do Colégio Aplicação tinham de história, resumido na questão nada simples: "O que você entende por história?". No entanto, críamos que esta questão sozinha não nos diria muita coisa, a não ser quando vinculada a outra que pudesse dar vazão explícita ao seu sentido ético-político: "para que você acha que deveríamos, então, estudá-la?". E, por fim, gostaríamos de saber quais as estratégias que utilizariam frente a uma possibilidade múltipla de versões e de diferentes suportes de linguagem com a seguinte questão: "Suponhamos que você fosse fazer um trabalho sobre um determinado tema em história, para apresentar em sala. Você ficou de assistir a um filme, pesquisar no Wikipédia e ler um texto referente ao assunto. Mas, percebeu que todos esses tinham opiniões diferentes. O que você faria e por que?".

O texto que elaboramos segue a linha dessas problematizações. Por tal razão, minimizaremos em nossa análise uma discussão mais aprofundada das questões socioculturais, não porque elas estejam desvinculadas das argumentações dos alunos a respeito de seus sentidos da 
história, mas por falta de tempo e espaço para realizá-las com mais afinco por ora. Desta forma, primeiro faremos uma breve discussão do que entendemos por "imaginação histórica" e quais os referenciais teóricos que adotamos para abordá-la em uma sala de aula. Em seguida, passaremos às respostas dos alunos para, ao fim, elencarmos algumas discussões e problematizações que tal tema nos suscitou.

Cabe advertir e ressaltar que não se tendeu aqui a analisar a trajetória de cada aluno em cada uma de suas respostas, de modo com que se pudesse observar seu desenvolvimento individual de uma a outra (ou pelo menos no que tange a "exposição" dos dados). Dessa forma, assumimos que realizamos uma abordagem mais geral das respostas, fazendo conexões entre uma e outra pergunta na medida em que julgamos pertinentes para exposição de nossos problemas. Dizemos isto para não criarmos falsas pretensões de uma unidade e estagnação de um "ser" classe primeiro $E$, nem fundamentos estanques que nada valeriam em um debate historiográfico sobre teoria e prática de ensino. Outro ponto que deve ser bem exposto é que não somos "especialistas" nessa área de estudo. Isto é dito não para nos redimir de responsabilidades das ideias aqui apresentadas, mas com intuito de evidenciar o lugar de onde falamos: a inquietação de dois alunos de curso de licenciatura em História postos diante à experiência da sala de aula.

\section{Imaginação Histórica em Debate: Algumas Precauções}

Para pensarmos a imaginação histórica acreditamos que duas ou três precauções são centrais e que necessitam ser esclarecidas previamente às formas como lemos as respostas dos alunos: primeiro que, como diz o teórico da educação em história Ivo Mattozzi, o texto e as conceitualizações têm (ou deveriam ter) um papel central no ensino de história (MATTOZZI, 2008), seja nos exercícios de interpretação das fontes (mas lembrando sempre que elas não se resumem somente à textualidade), seja na própria construção do texto pelos alunos em sala de aula. Ao dizermos isso, acreditamos que estendemos para a sala de aula toda a preocupação sobre 
a linguagem na historiografia que tem fomentado discussões $e$ posicionamentos dos mais variados durante os, no mínimo, últimos quarenta anos.

Em segundo lugar, complementando essa primeira observação, mas distanciando-nos um pouco das considerações pormenorizadas de Mattozzi, aproximamo-nos do que afirma Hayden White quando, em diálogo com Jacques Barzun sobre sua prática de "ensinar história", enuncia:

a 'história' que é o tema de todo esse aprendizado [escolar] só é acessível por meio da linguagem; que nossa experiência da história é indissociável de nosso discurso sobre ela; que esse discurso tem que ser escrito antes de poder ser digerido como 'história'; e que essa experiência, por conseguinte, pode ser tão vária quanto os diferentes tipos de discurso com que nos deparamos na própria escrita da história (WHITE, 1991, p. 21)

A um só tempo, com essa noção de White, a história, ou melhor, a escrita da história, essa "estrutura verbal na forma de um discurso narrativo em prosa" (WHITE, 2008, p. 17), passa a ser a expressão de uma determinada forma de experiência da história, que se configura como um campo de possibilidades plurais destas mesmas perspectivas/experiências. Se lermos somente até aqui o que White nos diz, certamente faríamos afirmações de seu "ultra-relativismo" e de sua inaplicabilidade em qualquer tentativa de ensino (Cf. BARCA, 2005, p. 30). No entanto, entre as suas teorias da urdidura do enredo historiográfico podemos destacar, de uma forma bastante geral e que atenda as nossas discussões, a correlação que faz entre as interpretações historiográficas possíveis e seus sentidos éticopolíticos: "A 'história' que estamos discutindo é aquela que toma forma na linguagem, na emoção, no pensamento e no discurso (...) trata-se de experiências antes de mais nada e acima de tudo políticas, e uma das maneiras de Ihes dar sentido é pensar sobre elas 'historicamente'" (WHITE, 1991, p. 32). Em outras palavras, podemos afirmar que, de maneira resumida, a construção daquilo que aqui tratamos pelo nome de "imaginação histórica" é algo construído dentro de uma conjuntura histórica, a partir de figuras linguísticas que atribuem significados e dão explicações aos eventos (MUNSLOW, 2009, p. 205-207) - os tropos, que 
para White os principais são ironia, metonímia, sinédoque e metáfora - que, por sua vez, tem sua historicidade e, portanto, é politicamente posicionada (WHITE, 2008, p. 46-52).

$\mathrm{Na}$ esteira das afirmações de White, de sua "explicação por implicação ideológica" (WHITE, 2008, p. 36-43), que nosso terceiro e último esclarecimento são as proposições de Keith Jenkins a respeito dessa relação entre as posturas ético-políticas e as questões epistemológicas da historiografia, ou seja, das relações entre o saber e o poder na construção da narrativa historiográfica. Para Jenkins, da mesma forma que White, uma vez que a narrativa sobre o passado não é o passado em si, e que essa característica não se resume ao fato único da escolha metodológica, a construção historiográfica está sempre preocupada e sempre direcionada ao outro. É em relação a este outro que vemos explicitamente seu caráter ideológico, em que "ela está constantemente sendo retrabalhada e reordenada por todos aqueles que, em diferentes graus, são afetados pelas relações de poder" (JENKINS, 2009, p. 40). Deste modo, as diferentes "versões" apresentadas na historiografia são entendidas como diferentes posicionamentos assumidos e inscritos nas relações de poder por aqueles que delas fazem uso. Não há centralidade na escrita da história, ou na "imaginação histórica", já que a própria centralidade evidencia uma postura assumida no interior dessas relações. Jenkins acaba por resumir, neste sentido, que "a história é teoria, e a teoria é ideologia, e a ideologia é pura e simplesmente interesse material" (JENKINS, 2009, p. 43).

Mas os alunos do primeiro ano do ensino médio foram obrigados a pensar, no momento em que responderam ao questionário, que suas visões de história têm, no fundo, interesse material? Claro que não. O que pretendemos ao explicitar nossas precauções é delimitar como veremos os lugares em que eles depositaram o sentido e a necessidade da disciplina de história - de acordo com as respostas à questão "O que você entende por história? A partir de sua resposta, para que você acha que deveríamos então estudá-la?". Da mesma forma, buscamos montar uma questão que os predispusesse a elaborar uma estratégia frente à diversidade de versões sobre um mesmo tema. Enfim, vamos às respostas e, mais à frente, a alguns questionamentos que elas nos suscitaram. 


\section{As Respostas Às Perguntas}

1. "O que você entende por história? A partir de sua resposta, para que você acha que deveríamos então estudá-la?"

As respostas a essa questão explicitaram, a um só tempo, elementos singulares - como traços narrativos mais ou menos explicativos e/ou descritivos - e mais gerais, como os discursos sobre o que é a história e o porquê de sua necessidade de estudos em sala de aula. A partir dessas enunciações sobre o que é a história elaboramos as seguintes categorias: primeiro, respostas que dizem que a história é o estudo sobre o passado; segundo, respostas que afirmam que a história são os acontecimentos no passado; terceiro, que a história pode ser tanto o estudo quanto os acontecimentos no passado; quarto e último, que aludiam que história é o tempo. Para uma melhor visualização do quadro geral das respostas, elaboramos o seguinte gráfico.

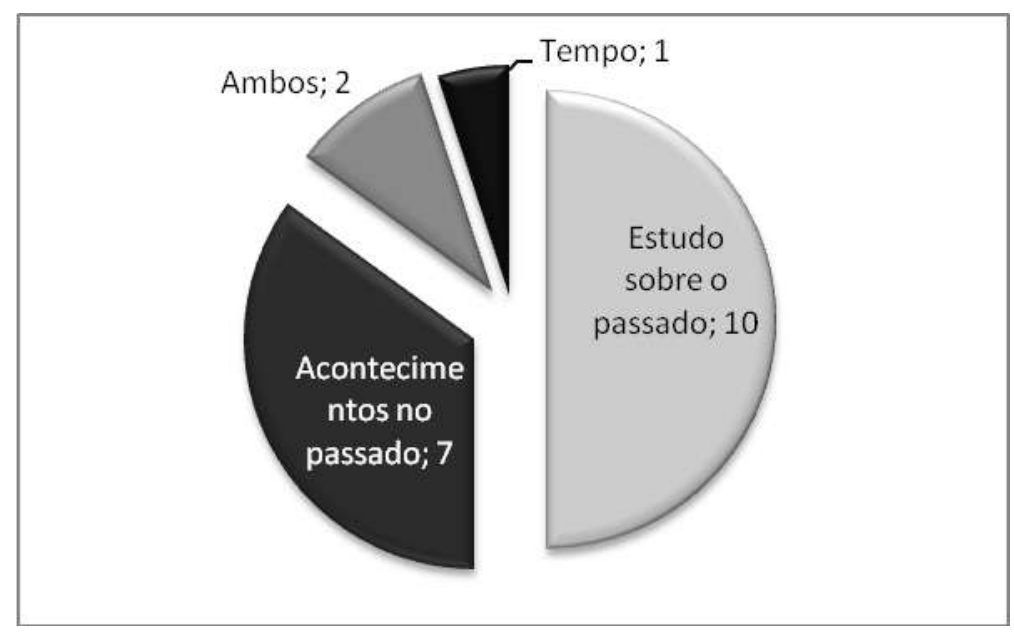

Gráfico 1 - Respostas à pergunta: "O que entende por história?".

É evidente que a maioria acredita que a história seja o estudo sobre passado - somando a metade dos que responderam. Dentre estes, percebemos que as respostas a continuidade da questão ("por que deveríamos estudá-la?"), em sua maior parte, estabeleciam-se relacionando tal estudo do passado a uma busca por origens, pelos "antepassados" (4/10), como podemos ver um exemplo na seguinte resposta: "[História] É 
o estudo de pontos importantes no passado. [Devemos estudá-la] Para conhecer as nossas origens e nossos antepassados".

Como também teve um aluno que respondeu que esse estudo do passado era algo próximo a uma velha ideia da Historia Magistra Vitae: "O estudo do passado, que serve para evitarmos que cometemos os mesmos erros do passado no futuro e presente".

Daqueles que acreditam que a história seja os acontecimentos no passado, dois alunos (2/7) relacionam que esses acontecimentos vieram a formar o mundo tal como ele é hoje, e, outros dois (2/7), colocam, de certa forma, que o passado vale somente enquanto um passado-em-si-mesmo, como uma espécie de conhecimento auto-suficiente que não se relaciona a nada no presente. O único aluno cuja resposta podemos notar alguma relação com a questão temporal não respondeu as outras questões. Já entre os que colocaram que a história pode ser tanto o estudo quanto os próprios acontecimentos, as respostas do porquê de seu estudo estão divididas entre uma busca pelo conhecimento das origens e uma história que vise à reflexão e ao debate. Colocaremos aqui esta última, devido a ser a única a colocar tal proposição, mesmo que num esforço quase que para agradar aqueles que posteriormente iriam ler: "História é conhecer o passado e as coisas que acontecem. Devemos estudar para compreender e entender, comentar, refletir, debater".

Podemos observar de maneira mais clara, em outro quadro geral, esses números sobre as proposições relativas ao porquê de se estudar história em sala de aula, agrupadas nas seguintes categorias: 


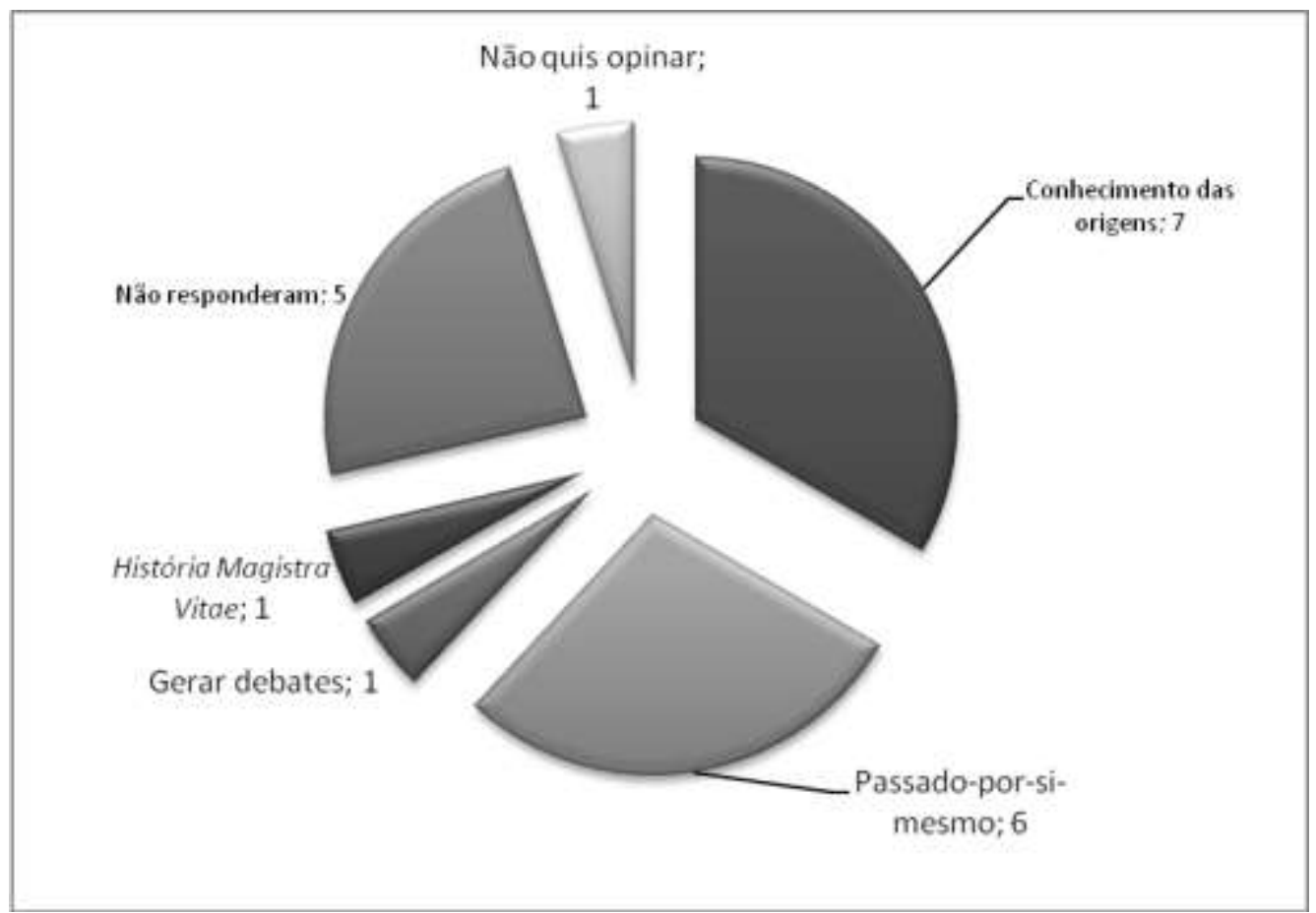

Gráfico 2 - Respostas à pergunta "para que você acha que deveríamos, então, estudá-la [história]?"

2. "Suponhamos que você fosse fazer um trabalho sobre um determinado tema em história, para apresentar em sala. Você ficou de assistir a um filme, pesquisar no Wikipédia e ler um texto referentes ao assunto. Mas, percebeu que todos esses tinham opiniões diferentes. O que você faria e por que?"

Antes de irmos às respostas, acreditamos que esta questão necessita de um pouco mais de explicação do porquê de sua configuração. Pensávamos, quando a elaboramos, em um modo de atingir alunos e alunas em uma situação cotidiana de sala de aula - o preparo de um trabalho - e, a partir disto, colocávamos um "problema" que gostaríamos de saber como eles lidariam: a diversidade de versões advindas de plataformas de linguagem diferentes, expressas pelas fontes de informações fílmicas, virtuais e a tradicional narrativa escrita em texto impresso.

Ainda cabe ressaltar que na parte do questionário destinada as questões socioculturais estavam presentes indagações a respeito, mesmo que de forma indireta, ao acesso, disponibilidade e preferência a esses três veículos comunicacionais. Dentre os vinte e dois alunos que realizaram o 
questionário, na questão sobre livros (livros favoritos) apenas três não a responderam. Quanto às questões relacionadas aos filmes (filmes favoritos), em particular, e a televisão (programas de televisão favoritos), em geral, foi grande a movimentação em comentar e expor as predileções dentro desses recursos, embora três alunos não tenham respondido sobre os filmes e um sobre os programas televisivos (talvez por conta da forma como a questão estava colocada). Ao responderem quantas horas de internet usavam por dia, nenhum aluno deixou de responder. A média geral foi duas horas em frente ao computador utilizando a internet, com respostas máxima de doze horas e mínima de uma hora, com enorme predomínio de acesso às redes sociais e sites de compartilhamento de vídeos.

Esse enorme parêntese foi para observarmos, antes mesmo das seguintes respostas, que todos os alunos, de uma forma geral, tinham um determinado acesso a pelo menos um dos três itens sugeridos na pergunta - pois ninguém ficou sem responder a todos eles, mesmo entre os alunos que assumiam que trabalhavam (nove entre os vinte e dois).

Voltando à questão: cinco alunos não a responderam. (Vamos confessar que isso nos deixou profundamente frustrados com nosso próprio desempenho - uma vez que não conseguimos tornar claro qual era a proposta da questão e por quais vias poderia ser respondidas - assim como também pode dar indícios de uma falta de articulação frente a esse problema, ou mesmo o cansaço de ter que ficar até para além das vinte e uma horas de uma sexta-feira à noite em uma sala de aula... enfim, as especulações podem ser inúmeras). De todo modo, agrupamos as respostas dos dezessete alunos que responderam em três grandes núcleos:

A) as respostas que fariam uma determinada análise comparativa de duas ou das três fontes e, a partir disso, construiriam uma síntese em busca da qual fosse a mais "verdadeira". Quase a metade dos que responderam, optaram por essa alternativa, totalizando oito alunos. Dentre estes, a resposta que dá a tônica geral de suas argumentações pode ser a seguinte: "Eu assistiria o filme e leria um texto referente ao assunto e a partir disso faria um resumo". 
B) Seis foram os alunos que responderam que fariam uso apenas de um recurso, o "mais confiável", "mais verdadeiro". Dos seis, quatro recorreriam à autoridade/confiabilidade do livro; dos outros dois, um recorreria ao que julgasse "mais interessante" e o outro apelaria ao conselho do professor para o "mais confiável".

C) Três alunos afirmaram em suas respostas que fariam uso, de certa forma, das múltiplas versões em seus trabalhos. Contudo, há de se fazer uma pequena distinção entre eles: enquanto um dos três procura, através do acúmulo de distintas perspectivas solidificar sua afirmação através de um amplo conhecimento, como podemos ver em sua resposta: "Eu procuraria apresentar as três opiniões de um modo geral, porque quanto mais opiniões você sabe, mais você vai saber sobre o assunto".

Os outros dois tem o intuito de apresentar as distintas perspectivas que contivesse em cada uma das plataformas: "Eu iria falar sobre os três, por mais que sejam diferentes devem ter algo em comum. Também eu iria falar dos três, porque tem três perspectivas".

\section{Interpretações e Questionamentos Possíveis: 0 "Fardo da História" e as "Paredes da Escola"}

Através dessa breve e geral exposição das respostas dos alunos, podemos dizer que o que ficam são questionamentos e problematizações. $\mathrm{E}$ a primeira é que, de um modo bastante esquemático, podemos dizer que a imaginação histórica em sala de aula, a partir desse nosso caso, anda mal. Anda mal não por conta de suas elaborações epistemológicas, pelos níveis aprofundados de conhecimento que os alunos não apresentam. Não, ela não vai mal por conta de elementos que atestem como os alunos são eruditos. Em nosso entendimento, a imaginação histórica vai mal por conta dos velhos lugares aos quais ela ainda ancora suas pesadas e longas pernas, os velhos lugares pelos quais ela ainda legitima sua existência.

Quer seja para agradar aquele que lê (no caso nós, estagiários, como também aos professores em geral), quer seja a expressão da própria experiência de um aluno que adentra ao primeiro ano do ensino médio, as 
construções que vimos através dos questionários sobre o que pode ser e quais as finalidades da história nos revelam, sobretudo, duas variantes que engessam a imaginação histórica: primeiro, quatorze dos dezessete que responderam sobre a finalidade da história colocaram-na sobre a égide ou da construção de um conhecimento que não tem nenhuma relação com o presente - um conhecimento de tipo autônomo e retroalimentativo -, ou, quando tem, essa construção é realizada a partir das narrativas que reivindicam uma origem conformativa e afirmativa, de cunho essencialista, de uma determinada identidade e/ou posição da realidade presente vivenciada, expressa na ênfase que vários demonstraram ao enunciarem "antepassados".

Em uma tonalidade semelhante é que vemos as respostas à questão que os coloca frente à diversidade narrativa acerca de um mesmo tema: de todos os dezessete alunos que responderam a questão, podemos notar que a grande maioria (14/17) embasa-se numa perspectiva de semelhança e/ou verdade única para com a multiplicidade. Refuta-se aquilo que é múltiplo através de duas grandes estratégias: ou pela síntese comparativa, que vai buscar o mesmo no diferente, construindo uma grande categoria verdadeira que englobasse as perspectivas distintas de acordo com suas utilidades práticas - no caso a apresentação do hipotético trabalho; ou a partir da recorrência de uma autoridade já dada, quer nos materiais de suporte - e aqui vemos a supremacia do livro, do texto impresso -, quer na única resposta que aponta o professor como aquele que definirá qual está "mais correto". Todavia, não nos esqueçamos dos três alunos que apresentariam as "diferentes opiniões" (mesmo que ainda percebamos em suas respostas alguns elementos que nos indicam certa continuidade com uma ideia de semelhança).

De todo modo, podemos dizer que a impressão geral que ficamos é de que a história é, paradoxalmente, aquilo que não corresponde ao presente e aquilo que deve ser primordialmente respeitado. Tanto o é que uma das respostas à primeira questão esquiva-se de responder a sua continuação ("para que deveríamos estudá-la?") e dá a seguinte justificativa: "Não me atreveria a dar uma opinião" (Grifos nossos). 
A história que a grande maioria dos alunos dá como possível (quando e se é que veem de fato alguma "utilidade" para história) é uma história extremamente pesada, tão pesada e, poderíamos dizer, autoritária que para poder falar sobre o porquê de serem (ou sermos) confinados e obrigados a estudá-la é "se atrever". Vemos nessas respostas algo que se assemelha ao que Hayden White (2001, p. 39-63) denominou, em 1966, de "fardo da história". Naquela ocasião White dialogava com os debates travados sobre qual a "natureza" da história, se ela estaria em um ponto neutro nas relações entre ciência e arte, entre objetividade e subjetividade. No entanto, aqueles que proclamavam esse ponto neutro da historiografia a viam com a perspectiva de uma ciência e de uma arte ambas do século XIX. A historiografia, para White, com tal argumentação, não teria dialogado com os desdobramentos no próprio interior das ciências e das artes, que apontavam para o caráter essencialmente provisório das construções metafóricas de que se valiam para compreender um universo polissêmico, estando ainda ligada a concepções unilaterais de verdade e continuidade.

A saída para todo esse peso, em White, estava em colocar a história como sensibilizadora dos elementos dinâmicos do presente, das mudanças que acontecem para aqueles que imaginam historicamente e que por isso mesmo, por sua vez, também são historicizáveis. Desta forma, segue que o "fardo do historiador" em nossa época seja aquele nada fácil de "libertar o presente do fardo da história". Nesse sentido, que continua a afirmar que:

O historiador contemporâneo precisa estabelecer o valor do estudo do passado, não como um fim em si, mas como um meio de fornecer perspectivas sobre o presente que contribuam para a solução dos problemas peculiares de nosso tempo (WHITE, 2001, p. 53)

Essa perspectiva não se diferencia das de muitos pesquisadores da historiografia, em geral, e de pesquisadores sobre o ensino de história, em particular (Cf. BITTENCOURT, 2004; MONTEIRO, 2003). No entanto, ela se choca com uma segunda problematização possível: sobre o tema da estrutura escolar (em uma ampla acepção). 
O que fizemos aqui foi elencar alguns problemas a partir das próprias concepções dos alunos sobre a imaginação histórica. Com isto não tínhamos por objetivo dar um basta a essa questão tão delicada e problemática. Mas, da mesma forma, não poderíamos ser omissos em nossas concepções e posicionamentos. Trazer as proposições de White e Jenkins para esse debate é agitar um campo de estudos que, por mais que insista em se reconstruir, ainda o faz sobre o mesmo tabuleiro. Os velhos modelos tanto da instituição jurídica escolar, quanto de sua própria arquitetura, ainda se fazem vivos após constantes depredações ao longo da segunda metade do século XX, às quais lembramos apenas as de Michel Foucault e Pierre Bourdieu.

A imagem veiculada do ensino ainda é aquela da "salvação", da "redenção", dentro ou fora das políticas governamentais e das instituições universitárias. No prefácio de sua tese de doutorado sobre a arqueologia da arquitetura escolar de Buenos Aires, posteriormente publicada em livro, Andrés Zarankin, ao contar sobre uma discussão envolvendo educação e Diego Maradona, afirma, frente à repressão que sofreu dos colegas sobre as críticas que começava fazer ao aspecto positivo da educação tradicional, que "teria sido mais fácil, e menos polêmico, questionar a existência de Deus do que a da escola e a da educação" (ZARANKIN, 2001, p. vi). Apesar da hipérbole dessa afirmativa, ela nos alerta de que necessitamos pensar outros meios de colocar os problemas da imaginação histórica seja dentro ou fora da instituição escolar. No entanto, se esses problemas passam por essas instâncias educacionais, precisamos, então, esforçar-nos novamente para saber, de fato, quais são os pesos e contrapesos dessa balança.

Desta forma, uma via possível é encaminhar nossos problemas como quando Viviane Mosé afirma, ao final de sua obra sobre a linguagem de Nietzsche, que: "a linguagem, além de ser nossa mediação com o mundo, com a vida, é a base do nosso sistema moral. Pensar a transvaloração dos valores é colocar em questão a linguagem" (MOSÉ, 2005, p. 232). Nesse sentido é que vemos a importância tanto das possibilidades do discurso historiográfico quanto da análise da narrativa de White que, embora não a utilizemos aqui em toda sua potencialidade para explorar a questão das 
imaginações históricas (no nosso caso dos alunos do ensino médio), fica somente a possibilidade (ou a provocação) de sua tentativa.

\section{Referências}

BARCA, I. Concepções de adolescentes sobre múltiplas explicações em História. In BARCA, I. (Org.). Perspectivas em Educação Histórica. Centro de Educação e Psicologia, Universidade do Minho, 2005.

BITTENCOURT, C. M. F. Ensino de História: fundamentos e métodos. São Paulo: Cortez, 2004.

JENKINS, K. A história repensada. Trad. Mario Vilela. São Paulo: Contexto, 2009.

MATTOZZI, I. Ensinar a escrever sobre história. História \& Ensino, trad. F. L. Iachtechen, Londrina, v. 14, p. 07-28, ago. 2008.

MONTEIRO, A. M. F. C. A história ensinada: algumas configurações do saber escolar. História \& Ensino, Londrina, v. 9, p. 37-62, out. 2003.

MOSÉ, V. Nietzsche e a grande política da linguagem. Rio de Janeiro: Civilização Brasileira, 2005.

MUNSLOW, A. Desconstruindo a história. Trad. R. G. Nascimento. Petrópolis: Vozes, 2009.

WHITE, H. O fardo da história. In Trópicos do discurso: Ensaios sobre a crítica da cultura. Trad. A. C. de Franca Neto. São Paulo: Editora da USP, 2001, p. 39-63.

. Meta-História: A imaginação histórica do século XIX. Trad. J. L. de Melo. São Paulo: Editora da USP, 2008.

. Teoria literária e escrita da história. In Estudos Históricos, trad. Dora Rocha, Rio de Janeiro, vol. 7, n. 13, p. 21-48, 1991.

ZARANKIN, Andrés. Paredes que domesticam: Arqueologia da arquitetura escolar capitalista: $\mathrm{O}$ caso de Buenos Aires. Tese de doutorado apresentada ao departamento de História do IFCH da Universidade Estadual de Campinas, Campinas, 2001. 